\title{
Depression Among HIV-Positive Pregnant Women at Northwest Amhara Referral Hospitals During COVID-19 Pandemic
}

\section{Hailemichael Kindie Abate Chilot Kassa Mekonnen (D) Yohannes Mulu Ferede}

Department Medical Nursing, University of Gondar, Gondar, Ethiopia
Correspondence: Hailemichael Kindie Abate

Email haile206k@gmail.com
Background: Depression is the most common mental health disorder among HIV-positive pregnant mothers, which increases mortality, poor quality of life; it also increases the burden of disease. Depression hurts birth outcomes and maternal health.

Objective: To assess depression and its associated factors among HIV-positive pregnant women attending antenatal care at Northwest Amhara referral hospitals, 2021.

Methods: An institution-based cross-sectional study was conducted among 291 HIVpositive pregnant mothers from March 15, 2021 to April 30, 2021 at Northwest Amhara referral hospitals. Census was applied to reach the study participants. An intervieweradministered questionnaire was used for data collection. A binary logistic regression was conducted to see the relationship between dependent variables and independent. Those variables having a $p$-value of $\leq 0.05$ were found to be statistically associated with the response.

Results: Depression among HIV-positive pregnant women was found to be $28.7 \%$ [ $95 \%$ CI (24.8-33.40)] with a response rate of 96.04. Age $\geq 30$ years $[\mathrm{AOR}=1.32,95 \%$ CI $(1.24$ $3.35)$ ], urban residency $[\mathrm{AOR}=1.76,95 \% \mathrm{CI}(1.57-4.61)]$, having first pregnancy $<18$ years $[\mathrm{AOR}=3.82,95 \% \mathrm{CI}(1.54-17.34)]$, known HIV serostatus during pregnancy $[\mathrm{AOR}=1.29$, 95\% CI (1.08-2.47)], and COVID-19-related knowledge [AOR $=0.32,95 \%$ CI $(0.12-1.12)$ were significantly associated with depression.

Conclusions and Recommendations: Nearly one-third of the pregnant women attending antenatal care were depressed. The age of the mother, residence, known HIV serostatus during pregnancy, age in the first pregnancy, and COVID-19-related knowledge were significantly associated with depression, and strengthening the existing care provided was the recalled interventions to combat antenatal depression during the COVID-19 pandemic.

Keywords: COVID-19, depression, prevalence, HIV positive mothers, pregnancy, referral hospitals, Ethiopia

\section{Background}

Depression is a sign and symptom complex experienced during the pregnancy period. ${ }^{1}$ The sudden occurrence of the COVID-19 pandemic with the surge in the number of infected cases and death has caused a serious and critical impact on public health including mental illnesses such as depression, sleep disturbance and other psychological disorders among the general public. ${ }^{2,3}$ The coronavirus disease 2019 (COVID-19) has resulted in unpredictable effects and is prone to people with severe depression. ${ }^{4}$ The World Health Organization reported that around $28 \%$ of the global burden of disease neuropsychiatric disorders occurred, of which one-third 
are due to depression. ${ }^{5}$ Evidence has shown that $15-23 \%$ of the pregnant women were prone to depression ${ }^{6,7}$ in comparison with $3-5 \%$ depression symptoms in the total population. ${ }^{8}$ The prevalence of depression in developing countries is ranged from $10 \%$ to $25 \%{ }^{9}$ Depressed individuals are prone at least as heavily disabled as individuals with the woman and her family. ${ }^{10}$

The COVID-19 pandemic has increased the level of depression because of the uncontrolled worry about their health for the safety of the fetus and the use of vaccines or medications for treatment and prophylaxis purposes. ${ }^{11} \mathrm{It}$ also increases the level of depression as a result of the effect of lockdown measures. ${ }^{12}$ The development of the unborn baby depends on the psychological health status of women during the time of pregnancy. ${ }^{13}$ Untreated depression can increase the risk of miscarriage, preterm labour, low Apgar score at birth, and low birth weight. ${ }^{14}$ It also induces mental and behavioural difficulties due to changes in brain function. ${ }^{15}$

During the era of COVID-19, depression in pregnant women was associated with age, marital status, occupation, education, parity, history of abortion, awareness of COVID-19, history of mental illness, and duration of pregnancy. ${ }^{16}$ Evidence also showed that factors like previous birth outcome, number of gravidities, number of parties, and history of pregnancy complications were found to be significant predictors of depression among HIV-positive women. ${ }^{17-20}$

In the context of the COVID-19 pandemic, maternal distress can be aggravated by worries and fears regarding the risk of infection and hospitalization due to COVID-19, especially as perinatal morbidity and mortality associated with COVID-19 of positive pregnant women have been described. Several patient groups including HIV-positive pregnant women were found to be more vulnerable to COVID-19 infection. COVID-19 was speculated to be poisoning a high risk to pregnant women due to superimposed immune system during pregnancy. ${ }^{21,22}$ Pregnant women can be challenged significantly due to the recommended restriction of social distancing, isolation, difficulty to get regular antenatal care visits, and fear to handle the baby. ${ }^{3}$ Identifying factors associated with increasing the burden of depression or protection from mental distress is vital to guide the development of effective prevention and intervention strategies. ${ }^{23}$ This study was new for the study area, and little is known at large in Ethiopia. Therefore, this study aimed to assess depression and its associated factors among HIV-positive pregnant women who had visited the three referral hospitals in northwest Amhara regional state, Ethiopia.

\section{Method \\ Study Design}

A multicenter institutional-based cross-sectional study was conducted.

\section{Study Area and Period}

This study was done in three Northwest referral hospitals (Gondar, Bahir Dar, and Debre Markos) found in the Amhara Regional State of Ethiopia. These hospitals are owned by the government and they serve above 19 million populations in the catchment area (Data from city woreda administration bureaus). The study was conducted from March 15, 2021 to April 30, 2021.

\section{Source Population}

All HIV-positive pregnant women who had visited the three referral hospitals were considered the source population.

\section{Study Population}

All HIV-positive pregnant women who had visited during data collection at the three referral hospitals were considered as the study population.

\section{Inclusion and Exclusion Criteria}

All randomly selected HIV-positive pregnant women to visit at three referral hospitals were found during the data collection time. HIV-positive pregnant mothers who were unable to communicate and seriously ill were excluded from the study.

\section{Sample Size Determination and Procedures}

The sample size of this study was calculated by using the single population proportion formula $\mathrm{n}=\left(\mathrm{Z} \frac{\alpha}{2}\right) 2 * \mathrm{p}(1-\mathrm{p}) /(\mathrm{d}) 2$. In the formula " $\mathrm{n}$ " denotes sample size, “ $\frac{\alpha}{2}$ ” is the reliability coefficient of standard error at the $5 \%$ level of significance with $z=1.96$, " $\mathrm{p}$ " is the proportion and " $\mathrm{d}$ " is the level of standard error. Taking into account the following assumptions; p-value of $50 \%(0.5)$, since there is no previous study, with a $95 \%$ confidence interval $(=0.05), 5 \%$ margin of error, and $10 \%$ to none response rate the final sample size was estimated as 423 . However, in these hospitals, 
there were a total of 303 HIV-positive pregnant mothers who had ANC follow-up during the data collection period. Therefore, we took all to participate in the study since it was less than the calculated sample 423. Therefore, a census was applied to reach the study participants. A structured questionnaire was used to conduct a face-to-to-face interview among participants attending ANC visits at selected referral hospitals in Northwest Amhara referral hospitals.

\section{Operational Definition of Variables}

Depression: The total score of $>10$ points on the PHQ-9 scale was categorized to have a depressive symptom. ${ }^{24}$

COVID-19-related knowledge: The participants who scored the mean above the mean $(\geq 12.25)$ had good knowledge, whereas participants who scored less than the mean $(<12.25)$ had poor knowledge. ${ }^{25}$

\section{Data Collection Tools and Procedures}

A structured interviewer-administered questionnaire was adapted from different kinds of literature. ${ }^{16,26,27}$ The questionnaire includes socio-demographic data, obstetric-related information, and HIV and psychosocial support-related information, and COVID-19-related knowledge questions. The COVID-19-related knowledge was assessed 16 questions with answer "Yes" (1 point) and "No" (0 points) options. The total knowledge score ranged from 0 to 16 . The participants who scored the mean and above the mean $(\geq 12.25$ ) had good knowledge, whereas participants who scored less than the mean $(<12.25)$ had poor knowledge. The levels of depression were assessed by using a nine-item patient's Health Questionnaire (PHO-9), which was validated in Ethiopia. Each component has a score of 0-3 with a score ranging from 0 to 27 . A total score of more than 10 indicates the presence of depressive symptoms. ${ }^{28}$ The reliability of the tool was ensured and the Cronbach's alpha for knowledge related to COVID-19 and depression items were 0.74 and 0.81 , respectively. The face validity of the tool was assessed by the experts in the area of this research and necessary modification had been done on each item of the tool. The questionnaire was initially prepared in English, then translated to Amharic, and then back to English to check its consistency. The Amharic version of the questionnaire was used for data collection. Data were collected using an interviewer-based structured questionnaire from each participant at selected referral hospitals in Northwest Amhara referral hospitals having ANC visits during the study period. Data collectors were the principal investigators (five in number). Upon data collection, the data collectors interviewed the participants independently to maintain transmitting of information or information bias between the participants.

\section{Data Quality Control}

The necessary correction was done after the pretest before the actual time data collection period. The collected data were checked for completeness and clarity accuracy by the principal investigators and data collectors. On the spot, the quality check was done every day to clear out the errors made during data collection. Data cleaning and crosschecking were done before the actual and further analysis.

\section{Data Processing and Analysis}

The data completeness and consistency were checked. The data were entered through Epi Info version 7. The data were cleaned accordingly and then exported to Statistical Package for Social Science (SPSS) version 20 software for further analysis. The missing data were handled by imputation (given code) in replacing the missing data with different values. Descriptive and summary statistics were used to describe the sample. Bivariable and multivariable logistic regression analysis was employed to identify variables associated with depression. The statistical association between independent and dependent variables was measured by using logistic regression analysis. Variables having a $p$-value $\leq 0.2$ in the bivariable analysis were considered for multiple logistic regression analysis to adjust for potential confounders and associated with the outcome variable in the final model. The odds ratio with its corresponding 95\% confidence interval was computed and interpreted accordingly. Finally, the result was presented using tables and text based on the data sets obtained.

\section{Result}

\section{Socio-Demographic Characteristics of Respondents}

Among a total of 303 study respondents, 291 were responding with a response rate of $96.04 \%$. The mean age of the respondents was $(30.37 \pm 5.12 \mathrm{SD})$. However the majority $(73.5 \%)$ and $(88.7 \%)$ of the respondents were married and urban dwellers, respectively. Of the participants $(65.3 \%)$ were Orthodox followers (Table 1$)$. 
Table I Socio-Demographic Characteristics of Participants Attending at Northwest Amhara Referral Hospitals, Ethiopia, $2019 / 2020(n=291)$

\begin{tabular}{|c|c|c|c|}
\hline \multicolumn{2}{|l|}{ Variables } & \multirow{2}{*}{$\begin{array}{l}\text { Frequency } \\
18 \mid\end{array}$} & \multirow{2}{*}{$\begin{array}{l}\text { Percentage (\%) } \\
62.2\end{array}$} \\
\hline Age in years & $<30$ & & \\
\hline & $\geq 30$ & 110 & 37.8 \\
\hline \multirow[t]{4}{*}{ Marital status } & Single & 39 & 13.4 \\
\hline & Married & 214 & 73.5 \\
\hline & Divorced & 26 & 8.9 \\
\hline & Widowed & 12 & 4.1 \\
\hline \multirow[t]{2}{*}{$\begin{array}{l}\text { Level of } \\
\text { education }\end{array}$} & $\begin{array}{l}\text { No formal } \\
\text { education }\end{array}$ & 72 & 24.7 \\
\hline & $\begin{array}{l}\text { Formal } \\
\text { education }\end{array}$ & 219 & 75.3 \\
\hline \multirow[t]{2}{*}{ Residence } & Urban & 258 & 88.7 \\
\hline & Rural & 33 & 11.3 \\
\hline \multirow[t]{4}{*}{ Religious } & Orthodox & 190 & 65.3 \\
\hline & Muslim & 71 & 24.4 \\
\hline & Protestant & 26 & 8.9 \\
\hline & Others & 4 & 1.4 \\
\hline \multirow[t]{2}{*}{ Occupation } & Employed & 88 & 29.1 \\
\hline & Unemployed & 203 & 12.7 \\
\hline \multirow[t]{4}{*}{ Ethnic group } & Amhara & 246 & 84.5 \\
\hline & Tigray & 19 & 6.5 \\
\hline & Oromo & 22 & 7.6 \\
\hline & Others & 4 & 1.4 \\
\hline
\end{tabular}

\section{Obstetric-Related Information of}

\section{Participants}

The majority (96.9\%) and (95.9\%) of the participants had $\geq 18$ years in their pregnancy and less than five pregnancies, respectively. Of the participants, $30.9 \%$ and $34.0 \%$ had a history of stillbirth and abortion, respectively (Table 2).

\section{HIV, Psychiatry, and Social Support Related Information of Participants}

The vast majority $(80.7 \%)$ of the participants had taken ART for less than 6 months. In the study, participants $(63.9 \%)$ were starting ART during pregnancy and
(56.3\%) had husband support. The depression among HIVpositive pregnant women was $28.7 \%$ [95\% CI (24.3-33.4)] at Northwest Amhara referral hospitals (Table 3).

\section{Factors Affecting Antenatal Depression Among HIV-Positive Pregnant Women}

In this study, among the variables entered in multivariable logistic regression, six variables were associated with the outcome variable of depression. In this regard, being $\geq 30$ years of age was nearly 1.62 times more $[\mathrm{AOR}=1.62,95 \%$ CI (1.24-3.35)] depressed compared to its counterpart, whereas being an urban residency was nearly two times [AOR $=1.76,95 \%$ CI (1.57-4.61)] to be depressed compared to being rural. Age at the first pregnancy was 3.82 times more $[\mathrm{AOR}=3.82,95 \% \mathrm{CI}(1.54-17.34)]$ depressed as compared with its counterpart. Those having known HIV serostatus during pregnancy were 1.29 times more [AOR $=1.29,95 \%$ CI (1.08-2.47)] depressed compared to its counterpart. The participants who had good COVID-19 knowledge were $68 \%\left[\begin{array}{lll}0.32 & (0.12-1.12)\end{array}\right]$ less likely depressed compared to poor COVID-19-related knowledge (Table 4).

\section{Discussion}

The finding of this study has assessed the depression of HIV-positive pregnant women in the Northwest referral hospitals, Amhara regional state of Ethiopia, which can be generalized peoples coming from the catchment area. As it is known, depression is the most common mental health disorder among HIV-positive pregnant mothers, which increases mortality, poor quality of life; it also increases the burden of disease during the era of COVID-19. This study showed that the magnitude of depression among HIV-positive pregnant mothers was found $28.7 \%$ with $95 \%$ CI (24.3-33.4).

The finding of this study was higher than the studies done in Malawi $(18.9 \%)^{29}$ and a systematic review conducted in Ethiopia (25.33\%). ${ }^{19}$ The possible reason might be because the study period in which the current study was conducted during the era of COVID-19. The finding of this study was lower than the studies conducted in India $(69.4 \%){ }^{26}$ Iran $(42.1 \%)^{30}$ and Canada $(29.4 \%, 35.21 \%$, $37 \%),{ }^{26,31,32}$ respectively. The possible explanation might be because of the higher transmission rates of COVID in India, Canada, and Iran, which lead to high depression in HIV-positive pregnant women. ${ }^{33,34}$ The finding of the study was also lower than the study conducted in Nigeria 
Table 2 Obstetric-Related Information of Participants Attending at Northwest Amhara Referral Hospitals, Ethiopia, 2019/2020 $(n=291)$

\begin{tabular}{|c|c|c|c|}
\hline Variables & Categories & Frequency & Percentage (\%) \\
\hline \multirow[t]{2}{*}{ Age in the first pregnancy } & $<18$ years & 9 & 3.1 \\
\hline & $\geq 18$ years & 282 & 96.9 \\
\hline \multirow[t]{2}{*}{ Number of pregnancy } & $<5$ & 279 & 95.9 \\
\hline & $\geq 5$ & 12 & 4.1 \\
\hline \multirow[t]{2}{*}{ History of problems in a previous pregnancy } & Yes & 118 & 40.5 \\
\hline & No & 173 & 59.5 \\
\hline \multirow[t]{2}{*}{ History of stillbirth } & Yes & 90 & 30.9 \\
\hline & No & 201 & 69.1 \\
\hline \multirow[t]{2}{*}{ Previous pregnancy-related hospitalization } & Yes & 118 & 40.5 \\
\hline & No & 173 & 59.5 \\
\hline \multirow[t]{2}{*}{ History of abortion } & Yes & 99 & 34.0 \\
\hline & No & 192 & 66.0 \\
\hline \multirow[t]{2}{*}{ Is the pregnancy planned } & Yes & 150 & 51.5 \\
\hline & No & 141 & 48.5 \\
\hline \multirow[t]{2}{*}{ ANC follow-up } & Yes & 194 & 66.7 \\
\hline & No & 97 & 33.3 \\
\hline \multirow[t]{2}{*}{ History of pregnancy-induced hypertension } & Yes & 158 & 54.3 \\
\hline & No & 133 & 45.7 \\
\hline \multirow[t]{2}{*}{ History of nausea and vomiting } & Yes & 126 & 43.3 \\
\hline & No & 165 & 56.7 \\
\hline
\end{tabular}

Abbreviation: ANC, antenatal care.

$(45.2 \%)^{35}$ and across European countries $(15 \%){ }^{27}$ The possible explanation may be due to the time gap for access to COVID-19-related information. ${ }^{36}$ This implies that the knowledge about COVID-19 can reduce the depression and anxiety level of people during COVID-19 by directing the promotion of health behaviours. ${ }^{37}$

In this study, among the variables entered in the multivariable logistic regression analysis, six variables were associated with the outcome variable of depression. In this regard, being $\geq 30$ years of age was nearly 1.62 times more to be depressed compared to age $<30$ years. This finding was in line with the study done in India. ${ }^{36}$ The finding is also supported by studies in South Africa and Atlanta Georgia. ${ }^{17,38}$ The possible explanation might be because as age increased there might be again hormonal changes responsible for mood disturbance. ${ }^{39}$

Having poor COVID-19 knowledge was 68\% less likely depressed than its counterpart. This finding was supported by a study done in Croatia. ${ }^{37}$ The possible explanation might be participants who had good knowledge of COVID-19 can decrease the virus propagation, which leads to a decrease in the level of depression. ${ }^{40}$ An urban residency was nearly twofold to be depressed compared to being rural. This finding was in line with the study done in India. ${ }^{16}$ The possible explanation might be because there could be lifestyle variations between urban and rural dwellers. The rural residency also has less information towards COVID-19 and does not have more 
Table 3 HIV, Psychiatry, and Social Support-Related Information of Participants Attending at Northwest Amhara Referral Hospitals, Ethiopia, $2019 / 2020(n=291)$

\begin{tabular}{|l|l|l|l|}
\hline Variables & Categories & Frequency & Percentage (\%) \\
\hline \multirow{5}{*}{ HIV exposure through } & Unsafe sex & 109 & 37.5 \\
\cline { 2 - 4 } & From family & 50 & 17.2 \\
\cline { 2 - 4 } & Sharing of sharps & 95 & 32.6 \\
\cline { 2 - 4 } & Others & 37 & 12.7 \\
\hline \multirow{2}{*}{ ART start } & Before pregnancy & 114 & 36.1 \\
\cline { 2 - 4 } & After pregnancy & 202 & 63.9 \\
\hline \multirow{2}{*}{ Duration of ART } & $<6$ months & 239 & 82.1 \\
\cline { 2 - 4 } & $\geq 6$ months & 52 & 17.9 \\
\hline \multirow{2}{*}{$\begin{array}{l}\text { Family history of psychiatric problems } \\
\text { Yes }\end{array}$} & No & 99 & 34.0 \\
\hline \multirow{2}{*}{$\begin{array}{l}\text { Husband support } \\
\text { women }\end{array}$} & Yes & 192 & 66.0 \\
\cline { 2 - 4 } & No & 170 & 58.4 \\
\hline
\end{tabular}

Abbreviations: ART, antiretroviral therapy; HIV, human immune virus.

concern/stress about the transmission as well as prevention mechanism of the pandemic. ${ }^{41}$

Having a first pregnancy $<18$ years was nearly four times to have depression in their pregnancy compared to $\geq 18$ years. This finding was supported by a study done in Iran. ${ }^{30}$ The possible explanation might be because those $<18$ years old pregnant women might have greater stress than the elders. They are under different pressure during the youth period, which makes them assume they lag behind their friends. This in turn increased their stress level and led them to be depressed. ${ }^{42}$ Those having known HIV serostatus during pregnancy was $29 \%$ more to be depressed compared to its counterpart. This finding was supported by the study done in Iran. ${ }^{16}$ The possible explanation might be because of the combined effect of COVID-19 and HIV on the level of depression during pregnancy of women. ${ }^{5,17,18}$

\section{Limitations of the Study}

The study was not conducting clinical confirmation for antenatal depression to ascertain the finding. Recall bias was a limitation in this study because of the selfreporting of the questionnaire by participants. The participants also might respond only to socially acceptable answers. The cross-sectional nature of the study cannot rule out the cause-effect relationship.

\section{Conclusion}

Although there was no clinical confirmation done for depression, nearly one-third of the pregnant women attending antenatal care were depressed during the era of the COVID-19 pandemic. Among the variables entered in the multivariable logistic regression analysis; the age of the mother, residence, known HIV serostatus during pregnancy, age in the first pregnancy, and COVID-19-related knowledge were independently associated with the outcome variable of depression. Therefore, the promotion of family planning and integration of maternal health care services with the existing care have to be strengthened as before during the era of COVID-19. 
Table 4 Bivariable and Multivariable Logistic Regression Analysis of Variables Predicting Antenatal Depression Among HIV-Positive Pregnant Mothers Attending Northwest Amhara Referral Hospitals, Ethiopia, 2019/2020 (n=29I)

\begin{tabular}{|c|c|c|c|c|c|}
\hline \multirow[t]{2}{*}{ Variables } & \multirow[t]{2}{*}{ Category } & \multicolumn{2}{|c|}{ Depression } & \multirow[t]{2}{*}{ COR $(95 \% \mathrm{Cl})$} & \multirow[t]{2}{*}{ AOR $(95 \% \mathrm{Cl})$} \\
\hline & & Yes & No & & \\
\hline \multirow[t]{2}{*}{ Age in years } & $<30$ & 39 & 142 & 1 & I \\
\hline & $\geq 30$ & 17 & 93 & $1.5(0.97-3.54)$ & $1.32(1.24-3.35)^{*}$ \\
\hline \multirow[t]{2}{*}{ Residence } & Urban & 46 & 212 & $2.0(0.89-4.49)$ & $1.76(1.57-4.61)^{*}$ \\
\hline & Rural & 10 & 23 & 1 & 1 \\
\hline \multirow[t]{2}{*}{ Educational status } & No formal education & 15 & 57 & 1 & I \\
\hline & Formal education & $4 I$ & 178 & $1.3(0.67-2.46)$ & $1.01(0.47-2.13)$ \\
\hline \multirow[t]{2}{*}{ Monthly income } & $\leq 1000$ ETB & 18 & 60 & $0.72(0.32-1.09)$ & $0.84(0.40-1.73)$ \\
\hline & $>1000 \mathrm{ETB}$ & 38 & 175 & I & I \\
\hline \multirow[t]{2}{*}{ Age in a first pregnancy } & $<18$ years & 5 & 4 & $5.66(|.47-2| .83)$ & $3.82(1.54-17.34)^{*}$ \\
\hline & $\geq 18$ years & 51 & 231 & I & 1 \\
\hline \multirow[t]{2}{*}{ Problem in previous pregnancy } & Yes & 20 & 98 & $1.28(0.84-2.90)$ & $1.06(0.54-2.08)$ \\
\hline & No & 36 & 137 & $\mathrm{I}$ & I \\
\hline \multirow[t]{2}{*}{ Planned pregnancy } & Yes & 22 & 128 & $0.54(0.29-1.98)$ & $0.47(0.26-1.79)$ \\
\hline & No & 34 & 107 & I & I \\
\hline \multirow[t]{2}{*}{ Depression in a previous pregnancy } & Yes & 8 & 63 & $2.19(0.87-4.04)$ & $1.45(0.32-4.67)$ \\
\hline & No & 48 & 172 & I & I \\
\hline \multirow[t]{2}{*}{ Time of knowing HIV serostatus } & Before pregnancy & 31 & 130 & 1 & $\mathrm{I}$ \\
\hline & After pregnancy & 25 & 105 & $0.99(0.51,1.64)$ & $1.29(1.08-2.47)^{*}$ \\
\hline \multirow[t]{2}{*}{ Family $\mathrm{HX}$ of psychiatric problem } & Yes & 12 & 87 & $2.16(0.97,3.75)$ & $1.94(0.88-4.28)$ \\
\hline & No & 44 & 148 & I & 1 \\
\hline \multirow[t]{2}{*}{ History of stillbirth } & Yes & 17 & 73 & $1.27(0.55,1.95)$ & $0.93(0.48-1.82)$ \\
\hline & No & 39 & 162 & I & 1 \\
\hline \multirow[t]{2}{*}{ Duration of ART } & $<6$ month & 49 & 190 & I & \\
\hline & $\geq 6$ month & 7 & 45 & $1.66(0.70,3.90)$ & $1.67(0.69-3.99)$ \\
\hline \multirow[t]{2}{*}{ Husband support } & Yes & 31 & 139 & $0.86(I .48, I .54)$ & $0.67(1.35-0.98)$ \\
\hline & No & 25 & 96 & I & I \\
\hline \multirow[t]{2}{*}{ Being happy with married } & Yes & 32 & 137 & $0.95(I .53, I .72)$ & $0.79(1.46-0.97)$ \\
\hline & No & 24 & 98 & I & 1 \\
\hline \multirow[t]{2}{*}{ COVID-related knowledge } & Good & 45 & 185 & I & 1 \\
\hline & Poor & 6 & 55 & $0.45(0.2 \mathrm{I}, \mathrm{I} .43$ & $0.32(0.12-1.12)^{*}$ \\
\hline
\end{tabular}

Note: *Indicates $P$ value less than 0.05 .

Abbreviations: COVID-19, coronavirus disease 2019; ETB, Ethiopian birr; HIV, human immune virus; AOR, adjusted odds ratio; COR, crude odds ratio.

\section{Abbreviations}

AIDS, acquired immune deficiency syndrome; AOR, adjusted odds ratio; ART, antiretroviral therapy; ARVS, antiretroviral drugs; BDI; Beck Depression
Inventory; COR; crude odds Ratio; HIV; human immunodeficiency virus; MBF; mixed breast feeding; MTCT; mother to child transmission; WHO; World Health Organization. 


\section{Data Sharing Statement}

The data could not be given to protect participants' confidentiality by far for this study. However, the whole summary data is available in the mother document.

\section{Ethical Approval and Consent to Participate}

The study was performed based on the ethical standards of put down the declaration of Helsinki. Ethical clearance was obtained from the institutional ethical review committee of the school of nursing and college of health science of University Gondar with ethical clearance letter reference number of Rf. No. S/N2013/06/2013. Permission and supportive letters were obtained from the respective clinical directors of each hospital. All participants of the study were well informed about the overall rationale of the study. They had got written informed consent to secure their confidentiality.

\section{Consent to Publish}

Consent to publish is not applicable.

\section{Acknowledgments}

Our deepest gratitude goes to the University of Gondar for all expenses of this research work and the study participants who participated in this research. The authors also would like to thank the respective Hospital admirers of Gondar, Bahir Dar, and Debre Markos. The authors also would like to give great appreciation to data collectors and supervisors for their contribution to this paper.

\section{Author Contributions}

All authors made a significant contribution to the work reported, whether that is, in the conception, study design, execution, acquisition of data, analysis and interpretation or in all these areas; took part in drafting, revising, or critically reviewing the article; gave final approval of the version to be published; have agreed on the journal to which the article has been submitted; and agree to be accountable for all aspects of the work.

\section{Funding}

The study was funded by the University of Gondar College of Medicine and Health Sciences. However, the funders have no significant role to play in the study design, data collection, analysis, and manuscript preparation.

\section{Disclosure}

All authors have declared that they have no conflicts of interest concerning this manuscript.

\section{References}

1. Rochat TJ, Richter LM, Doll HA, Buthelezi NP, Tomkins A, Stein A. Depression among pregnant rural South African women undergoing HIV testing. JAMA. 2006;295(12):1373-1378. doi:10.1001/ jama.295.12.1376

2. Sharma R, Vishwas A, Jelly P. Impact of COVID-19: nursing perspective and concern. Int J Community Med Public Heal. 2020;7 (11):4648-4652. doi:10.18203/2394-6040.ijcmph20204769

3. Allotey J, Stallings E, Bonet M, et al. Clinical manifestations, risk factors, and maternal and perinatal outcomes of coronavirus disease 2019 in pregnancy: living systematic review and meta-analysis. $B M J$. 2020;370:m3320.

4. Soto-Balbuena C, Rodriguez M, Escudero Gomis AI, Ferrer Barriendos FJ, Le H-N, Pmb-Huca G. Incidence, prevalence and risk factors related to anxiety symptoms during pregnancy. Psicothema. 2018;30(3):257-263. doi:10.7334/psicothema2017.379

5. Bitew T. Prevalence and risk factors of depression in Ethiopia: a review. Ethiop J Health Sci. 2014;24(2):161-169. doi:10.4314/ejhs.v24i2.9

6. Nath S, Ryan EG, Trevillion K, et al. Prevalence and identification of anxiety disorders in pregnancy: the diagnostic accuracy of the two-item Generalised Anxiety Disorder scale (GAD-2). BMJ Open. 2018;8(9):e023766. doi:10.1136/bmjopen-2018-023766

7. Sasaki T-K, Yoshida A, Kotake K. Attitudes about the 2009 H1N1 influenza pandemic among pregnant Japanese women and the use of the Japanese municipality as a source of information. Southeast Asian J Trop Med Public Health. 2013;44(3):388-399.

8. Sinesi A, Maxwell M, O'Carroll R, Cheyne H. Anxiety scales used in pregnancy: a systematic review. BJPsych Open. 2019;5(1). doi:10.1192/bjo.2018.75

9. Martini J, Petzoldt J, Einsle F, Beesdo-Baum K, Höfler M, Wittchen H-U. Risk factors and course patterns of anxiety and depressive disorders during pregnancy and after delivery: a prospective-longitudinal study. J Affect Disord. 2015;175:385-395. doi:10.1016/j.jad.2015.01.012

10. Ahmed T, Hossain M, Sanin KI. Global burden of maternal and child undernutrition and micronutrient deficiencies. Ann Nutr Metab. 2012;61(Suppl. 1):8-17. doi:10.1159/000345165

11. Brooks SK, Weston D, Greenberg N. Psychological impact of infectious disease outbreaks on pregnant women: rapid evidence review. Public Health. 2020;189:26-36. doi:10.1016/j.puhe.2020.09.006

12. Haghdoost SM, Gol MK. The necessity of paying more attention to the neurological and psychological problems caused by the COVID-19 pandemic during pregnancy. Health. 2020;3:4.

13. Chen S, Zhuang J, Chen Q, Tan X. Psychological investigation on pregnant women during the outbreak of COVID-19; 2020.

14. Grigoriadis S, Graves L, Peer M, et al. Maternal anxiety during pregnancy and the association with adverse perinatal outcomes: systematic review and meta-analysis. J Clin Psychiatry. 2018;79(5). doi:10.4088/JCP.17r12011.

15. Glover V. Maternal depression, anxiety and stress during pregnancy and child outcome; what needs to be done. Best practice \& research. Clin Obstet Gynaecol. 2014;28(1):25-35.

16. Jelly P, Chadha L, Kaur N, et al. Impact of COVID-19 pandemic on the psychological status of pregnant women. Cureus. 2021;13(1): e12875.

17. Blaney NT, Fernandez MI, Ethier KA, et al. Psychosocial and behavioural correlates of depression among HIV-infected pregnant women. AIDS Patient Care STDS. 2004;18(7):405-415. doi:10.1089 /1087291041518201 
18. Bonacquisti A, Geller PA, Aaron E. Rates and predictors of prenatal depression in women living with and without HIV. Aids Care. 2014;26(1):100-106. doi:10.1080/09540121.2013.802277

19. Getinet W, Amare T, Boru B, Shumet S, Worku W, Azale T. Prevalence and risk factors for antenatal depression in Ethiopia: a systematic review. Depress Res Treat. 2018:2018. doi:10.1155/ 2018/3649269

20. Logie C, James L, Tharao W, Loutfy M. Associations between HIV-related stigma, racial discrimination, gender discrimination, and depression among HIV-positive African, Caribbean, and Black women in Ontario, Canada. AIDS Patient Care STDS. 2013;27 (2):114-122. doi:10.1089/apc.2012.0296

21. Westgren M, Pettersson K, Hagberg H, Acharya G. Severe maternal morbidity and mortality associated with COVID-19: the risk should not be downplayed. Acta Obstet Gynecol Scand. 2020;99 (7):815-816. doi:10.1111/aogs. 13900

22. Favre G, Pomar L, Baud D. Coronavirus disease 2019 during pregnancy: do not underestimate the risk of maternal adverse outcomes. Am J Obstet Gynecol. 2020;2(3):100160.

23. Wang $\mathrm{C}$, Pan $\mathrm{R}$, Wan $\mathrm{X}$, et al. Immediate psychological responses and associated factors during the initial stage of the 2019 coronavirus disease (COVID-19) epidemic among the general population in China. Int $J$ Environ Res Public Health. 2020;17(5):1729. doi:10.3390/ijerph17051729

24. Kim MH, Mazenga AC, Devandra A, et al. Prevalence of depression and validation of the beck depression inventory-II and the children's depression inventory-short amongst HIV-positive adolescents in Malawi. $J$ Int AIDS Soc. 2014;17(1):18965. doi:10.7448/IAS.17.1.18965

25. Nigussie TF, Azmach NN. Knowledge, attitude and practice towards covid-19 among Arba Minch town, southern Ethiopia. GSJ. 2020;8 (6):1283-1307.

26. Tomfohr-Madsen LM, Racine N, Giesbrecht GF, Lebel C, Madigan S. Depression and anxiety in pregnancy during COVID-19: a rapid review and meta-analysis. Psychiatry Res. 2021;300:113912. doi:10.1016/j.psychres.2021.113912

27. Ceulemans M, Foulon V, Ngo E, et al. Mental health status of pregnant and breastfeeding women during the COVID-19 pandemic -A multinational cross-sectional study. Acta Obstet Gynecol Scand. 2021;100(7):1219-1229. doi:10.1111/aogs.14092

28. Gelaye B, Williams MA, Lemma S, et al. Validity of the patient health questionnaire-9 for depression screening and diagnosis in East Africa. Psychiatry Res. 2013;210(2):653-661. doi:10.1016/j. psychres.2013.07.015

29. Dow A, Dube Q, Pence BW, Van Rie A. Postpartum depression and HIV infection among women in Malawi. J Acquir Immune Defic Syndr. 2014;65(3):359. doi:10.1097/QAI.0000000000000050

30. Hamzehgardeshi Z, Omidvar S, Amoli AA, Firouzbakht M. Pregnancy-related anxiety and its associated factors during COVID-19 pandemic in Iranian pregnant women: a web-based cross-sectional study. BMC Pregnancy Childbirth. 2021;21(1):1-9. doi:10.1186/s12884-021-03694-9

Risk Management and Healthcare Policy

\section{Publish your work in this journal}

Risk Management and Healthcare Policy is an international, peerreviewed, open access journal focusing on all aspects of public health, policy, and preventative measures to promote good health and improve morbidity and mortality in the population. The journal welcomes submitted papers covering original research, basic science, clinical \& epidemiological studies, reviews and evaluations,
31. Racine N, Hetherington E, McArthur BA, et al. Maternal depressive and anxiety symptoms before and during the COVID-19 pandemic in Canada: a longitudinal analysis. Lancet Psychiatry. 2021;8 (5):405-415. doi:10.1016/S2215-0366(21)00074-2

32. Lebel C, MacKinnon A, Bagshawe M, Tomfohr-Madsen L, Giesbrecht G. Elevated depression and anxiety symptoms among pregnant individuals during the COVID-19 pandemic. $J$ Affect Disord. 2020;277:5-13. doi:10.1016/j.jad.2020.07.126

33. Ho CS, Chee CY, Ho RC. Mental health strategies to combat the psychological impact of COVID-19 beyond paranoia and panic. Ann Acad Med Singapore. 2020;49(1):1-3.

34. Ettman CK, Abdalla SM, Cohen GH, Sampson L, Vivier PM, Galea S. Prevalence of depression symptoms in US adults before and during the COVID-19 pandemic. JAMA Netw Open. 2020;3(9): e2019686-e. doi:10.1001/jamanetworkopen.2020.19686

35. Nwafor JI, Okedo-Alex IN, Ikeotuonye AC. Prevalence and predictors of depression, anxiety, and stress symptoms among pregnant women during COVID-19-related lockdown in Abakaliki, Nigeria. Malawi Med J. 2021;33(1):54-58. doi:10.4314/mmj.v33i1.8

36. Poudel K, Subedi P. Impact of COVID-19 pandemic on socioeconomic and mental health aspects in Nepal. Int J Soc Psychiatry. 2020;66(8):748-755. doi:10.1177/0020764020942247

37. Galić M, Mustapić L, Šimunić A, Sić L, Cipolletta S. COVID-19 related knowledge and mental health: case of Croatia. Front Psychol. 2020;11:817. doi:10.3389/fpsyg.2020.00011

38. Rochat TJ, Tomlinson M, Newell M-L, Stein A. Detection of antenatal depression in rural HIV-affected populations with short and ultrashort versions of the Edinburgh Postnatal Depression Scale (EPDS). Arch Womens Ment Health. 2013;16(5):401-410. doi:10.1007/ s00737-013-0353-z

39. van den Beld AW, Kaufman J-M, Zillikens MC, Lamberts SW, Egan JM, van der Lely AJ. The physiology of endocrine systems with ageing. Lancet Diabetes Endocrinol. 2018;6(8):647-658. doi:10.1016/S2213-8587(18)30026-3

40. Islam MS, Rahman KM, Sun Y, et al. Current knowledge of COVID-19 and infection prevention and control strategies in healthcare settings: a global analysis. Infect Control Hosp Epidemiol. 2020;41(10):1196-1206. doi:10.1017/ice.2020.237

41. Kassa AM, Mekonen AM, Yesuf KA, Tadesse AW, Bogale GG. Knowledge level and factors influencing prevention of COVID-19 pandemic among residents of Dessie and Kombolcha City administrations, North-East Ethiopia: a population-based cross-sectional study. BMJ Open. 2020;10(11):e044202. doi:10.1136/bmjopen2020-044202

42. Nakamura Y, Okada T, Morikawa M, et al. Perinatal depression and anxiety of primipara is higher than that of multipara in Japanese women. Sci Rep. 2020;10(1):1-10. doi:10.1038/s41598-020-74088-8 guidelines, expert opinion and commentary, case reports and extended reports. The manuscript management system is completely online and includes a very quick and fair peer-review system, which is all easy to use. Visit http://www.dovepress.com/testimonials.php to read real quotes from published authors.

\section{Dovepress}

